\title{
The transition to adulthood across time and space: overview of Special Section
}

\author{
John Schulenberg \\ University of Michigan, Ann Arbor, USA \\ schulenb@isr.umich.edu \\ Ingrid Schoon \\ Institute of Education, University of London, London, UK
}

\section{Introduction}

In this Special Section of Longitudinal and Life Course Studies, we provide complementary findings from four well-established national and community-based studies about distinct patterns of social role combinations in early adulthood, along with the antecedents and health and well-being correlates of the distinct patterns (Maggs et al 2012, Räikkönen, Kokko and Pulkkinen 2012, Salmela-Aro, Ek and Chen 2012, Schoon et al 2012). Collectively, our data span two birth cohorts (born 1958-59 and 1966-70) and three countries including Great Britain (GB), the United States (US), and Finland, with each birth cohort represented in each country. This opportunity to compare and contrast patterns of transition outcomes across time and across cultures provides us with leverage on the understanding of the transition to adulthood not typically available.

Across the studies, longitudinal data span childhood through early adulthood. Each study focuses on identifying distinct patterns of role combinations by ages $25-27$ in terms of the "big 5 " transition markers (Settersten 2007) comprising educational attainment, work status, independent living, romantic partnership, and parenthood. It has been argued that country differences in completing the five transition markers are largest around age 25 and relatively small before age 20 and after age 35 (Cook and Furstenberg 2002). Examining transition outcomes and role combinations of cohort members in their mid-20s thus provides a unique snapshot and important insights into similarities and differences in transition experiences of young people growing up in different cultural contexts and in different historical periods. For example, consistent with previous research (Osgood et al 2005, Ross et al 2009), some common patterns we found include "traditional family" (limited college, full-time employed or homemaker, independent from parents, married or cohabiting, and with children) and "work orientation without children" (college graduate, full-time employed, independent from parents, average rates of marriage and cohabitation, and no children).

Each study also examines the demographic and educational antecedents and psychosocial correlates/outcomes of the patterns (including well-being and substance use). As will be shown, we find some expected differences across countries and cohorts in terms of configurations and prevalences of the distinct patterns, along with some remarkable similarities across time and space in these patterns and their antecedents and correlates. To set the stage for the empirical papers in this Special Section, we provide an overview regarding the transition to adulthood in developmental, historical, and international context. We furthermore discuss methodological opportunities and challenges involved in describing life course patterns and doing comparative research. We conclude with consideration of theoretical and methodological implications. 


\section{Key issues in the study of the transition} to adulthood in developmental, historical and international context

\section{International and interdisciplinary comparisons and collaborations}

Cross-study comparisons in general, and international comparisons in particular, are essential for theory advancement in our understanding of the transition to adulthood. Such studies assist in matters of generalizability as well as in considering how country-level culture and expectations play out in terms of developmental opportunities and constraints (Jensen 2011). Despite many similarities across GB, the US, and Finland, there are some clear differences in educational opportunities and independence expectations. In particular, the three countries differ regarding academic and vocational tracking in secondary school (explicit split at age 16 in $\mathrm{GB}$ and Finland; opaque and less formal tracking in the US) and public funding of post-secondary college (fully funded in GB until 1998, fully funded in Finland, and largely self-funded in the US). Furthermore, the Finnish welfare state supports the move to independent living among young people, and postsecondary students are entitled to social security support; this is not the case in GB and the US. As we will see, a consequence is that by age 25-27, most Finns - in both birth cohorts - live independently from their parents, while in GB and US we find, in both cohorts, a distinct group of young people who at age 25-27 are living with one or both parents (having either never left, or returning to the parental home after difficulties in launching). When looking across countries, similarities and differences in the transition to adulthood can be examined in terms of the distinct patterns (regarding the number of distinct patterns, the transition configurations that make up the distinct patterns, and the prevalences of distinct patterns) and/or in terms of the antecedents, correlates, and outcomes of the patterns. Of course, cross-country comparisons depend on similarities in methods; for us, although constructs are remarkably similar across countries, sampling frames are not, especially in the two Finnish studies.

Because the transition to adulthood covers such a wide set of domains at multiple levels, spanning neurological development underlying improved executive functioning (e.g. Burt and Masten 2010; Spear 2010) to cultural expectations about "developmental timetables" (e.g. Heckhausen 2010), a fuller understanding of this period in life demands an inter-disciplinary perspective (Schoon and Silbereisen 2009; Schulenberg and Maggs 2002; Settersten 2007). In this inter-disciplinary collaboration we take into account social structuring of the life course, agency in the form of educational aspirations, objective transition markers, and subjective experiences in terms of well-being and life satisfaction; in particular, we give attention to both social structure and individual development, illustrating the notion of bounded agency (Heinz 2009; Shanahan 2000). Ultimately, we believe that this collaboration represents the gains that can come from developmental scientists and sociologists "playing well together" to examine how this time of life is experienced across countries and cohorts.

\section{Interplay of historical change and individual development}

In many ways, the qualities of the transition to adulthood, particularly the density of potential life changes (Shanahan 2000), make it an important nexus of individual development and historical change, how historical change influences individual development and how individual development in the aggregate can influence historical change (Johnson, Crosnoe and Elder 2011). For example, the age of first marriage has increased by several years over the past few decades, and this no doubt was partly an interactive process whereby the shifting norms about marriage contributed to individual behavior which then aggregated to constitute a new historical context for following cohorts. Furthermore, there has been an expansion and elongation of education participation, especially among women and those from less privileged backgrounds (Schoon and Silbereisen 2009); likewise, there has been increasing participation of women in the labour market, reflecting the changing nature of job opportunities and a labour market characterized by an increasing demand for skilled labour and non-manual, nonroutine occupations (Blossfeld 2005). Again, this reflects an interactive process, as shifting 
opportunities and norms set the stage for individual behaviors which then aggregate to form a new historical context for subsequent cohorts.

As is true regarding cross-country comparisons in the transition patterns, an important consideration when examining historical change in the transition to adulthood is the extent to which there is historical variation in the patterns (in terms of the number and configurations of the distinct patterns, as well as the prevalences of distinct patterns) and/or in the antecedents, correlates, and outcomes of the patterns. It has been argued that since the 1970s traditional pathways into adult life have become destandardised, more heterogeneous and differentiated, suggesting for us an increase in the number of distinct patterns and changes in the configuration of roles in the patterns across cohorts. It has also been argued that there is an increase in individualisation across cohorts, with individual agency serving a greater role in shaping the life course (Beck 1992; Giddens 1991); for us, this suggests an increase across cohorts in the power of agency, taking the form of educational aspirations, to predict the distinct transition patterns. Within each country, these considerations are undertaken across the two cohorts with evidence suggesting cohort similarities in numbers and configurations of patterns, but some changes in prevalences of patterns across cohorts; in addition, educational aspirations are found to gain more power across cohorts in the US, but so does parental education, suggesting that increases in agency are balanced by increases in social structure. Of course, much depends on similarities in methods across cohorts, and as we see, there is variation in samples and measurement across history, especially in the two Finnish studies.

\section{The importance of the transition to adulthood}

Among the many global life transitions across the lifespan, this transition ranks very high in terms of importance, complexity, and uniqueness. It is when educational and life plans formulated up through adolescence - often with considerable individual and societal investment - meet the opportunities and constraints of post-adolescent life. In particular, it is when one typically confronts, or at least becomes familiar with, the necessity of compromise in the interplay of competing life goals. This helps make it a potentially critical life transition in terms of ongoing health and well-being (Schulenberg, Maggs and O'Malley 2003). It is also a demographically dense period (Shanahan 2000) with multiple transitions related to social role, residence, work, and education, all within a relatively short time. A common-sense belief about transitions, and one that works well in understanding the global transition into adolescence, is that multiple simultaneous transitions result in reduced health and well-being (Coleman 1989; Schulenberg and Maggs 2002). Yet, this is not what is found regarding the transition to adulthood; indeed, evidence from the four studies in this Special Section suggests that those who by age 26 successfully negotiate the multiple transitions that comprise the global transition to adulthood, end up looking better than their age-mates in terms of health and wellbeing (Maggs et al 2012; Räikkönen et al 2012; Salmela-Aro 2012; Schoon et al 2012). Similar findings have been reported by other studies conducted in the US (e.g. Schulenberg, Bryant and O'Malley 2004) and in Britain (Sacker and Cable 2010). For most, by the mid-20s, educational pursuits and exit from the parental home are complete. Yet, there is still considerable heterogeneity in experiences that reflect the pace of one's progression along adult social role transitions, experiences, and responsibilities. We were fortunate to have in each study, data collections at ages 25-27 to assess commonalities and variations in transition outcomes across countries and across different historical periods.

\section{Placing the transition to adulthood within a developmental context}

Another important aspect of the four studies is that they attend to how experiences connect across the life course, whereby childhood and adolescent experiences and decisions set the course for transitions experienced during the middle 20s, and likewise how these transition patterns set the stage for continued health and well-being. Key gaps in the literature pertain to the failure to view this period from adolescence to adulthood in a longer-term developmental perspective (Bynner 2005). For example, despite the needed attention that the concept of emerging adulthood (Arnett 2000) has brought to the age period, especially among some psychologists, much of the relevant research has 
focused only on experiences during this age period, with little regard for developmental and sociodemographic antecedents and long-term consequences. As a result, the extent to which experiences during this age period reflect developmental continuity or discontinuity remains a critical gap. Thus the four studies in this Special Section, by focusing on socio-demographic and adolescent predictors of the different transition patterns, contribute to understanding how pathways through this period are embedded within the life course.

\section{Heterogeneity in life paths and the fanning of health and well-being trajectories}

The transition to adulthood is characterized by increased heterogeneity in life paths (Ross et al 2009; Schulenberg et al 2003). During adolescence, life roles tend to be fairly homogenous; with the conclusion of secondary education, diversity in pathways becomes more manifest, as many young people enjoy greater selection of contexts and experiences along with increased agency. Our studies clearly illustrate this heterogeneity, showing that there is not one normative way to negotiate this global life transition. At the same time, it is quite clear that structural forces, as mediated by the family and local opportunity structures, and agency, as represented by educational aspirations, help create this heterogeneity by shaping the timing and sequencing of transitions to independent adulthood.

Along with the increased heterogeneity of pathways during the transition to adulthood, there is increased heterogeneity in health and well-being trajectories. This increased "fanning" is sometimes referred to as the "Matthew Effect" whereby those who are already doing well have the psychological and social resources to rise to the occasion and successfully negotiate the various transitions, and those already having difficulties fall further behind as they try to negotiate the transitions (Dannefer 1987; Schulenberg and Zarrett 2006). The present set of studies sheds light on the importance of, and mechanisms embedded within, the transition to adulthood in terms of the increasing heterogeneity in health and well-being. Clearly, embedded within this global transition are mechanisms for both continuing and interrupting ongoing trajectories of health and well-being (Schulenberg and Maggs 2002), and as the studies here show, making firm commitments and getting on with adulthood tend to be associated with higher life satisfaction and well-being.

\section{Methodological opportunities and challenges}

\section{Conceptualising life course patterns}

Within life course theory (Elder 1985) transitions denote changes in status or social roles, such as leaving school and entering full-time employment. Transitions are usually short in duration and indicate a change in a single state, moving from one social role or status to another. Transitions are embedded within trajectories that give them a distinctive form and meaning. Trajectories take place over an extended period of time and capture sequences of roles and experiences. The life course is, however, not defined by transitions and trajectories as such, but is characterized by the interplay of multiple role transitions and trajectories. The combination of multiple social roles at a given time has been conceptualised by the notion of role or status configurations to describe age-specific matrices of discrete social roles that individuals occupy at given points in the life course (Macmillan and Eliason 2003).

Although the transition to adulthood has attracted much research, most studies have concentrated on only one type of transition at a time, such as the transition from education into employment, or the transition into parenthood (Rindfuss 1991; Shanahan 2000). Typically these studies have used event-history models to examine the timing of and the precursors to these transition markers. The unfolding of the life course however, necessitates the assumption of multiple new social roles, such as leaving full-time education, entry into paid employment, settling down with a partner, and becoming a parent (Buchmann and Kriesi 2011; Modell, Furstenberg and Hershberg 1976; Shanahan 2000). Transitions such as leaving school, entry into the labour market, and timing of first birth are not discrete, clearly bounded events - but are interdependent, often requiring compromises and coordination of different demands (Shanahan and Elder 2006). Failure to recognize this 
interdependence constitutes a key gap in the literature, and addressing this gap is at the core of the four studies in this Special Section, conceptually and methodologically.

\section{Dependencies among social role transitions set the stage for analysis of distinct patterns.}

The interdependence of education, work and family-related transitions suggests the need for empirical methods that account for the multidimensional associations between variables, enabling the simultaneous consideration of multiple dimensions, which interact in important ways. In particular, each study takes a patterncentered approach to account for functioning within individuals across multiple domains, using latent class analysis (LCA) to uncover the distinct patterns showing the different ways that the social roles fit together. Thus, together, these studies provide a more holistic understanding of the interdependence and combinations of social roles within individuals and the social structuring of the life course. LCA is a statistical method that enables us to examine latent structures among a set of categorical scored variables and to identify underlying types, groups, or classes (Goodman 1974; Lazarsfeld and Henry 1968). The usefulness of the latent class approach to map out diversity and heterogeneity in role configurations has been demonstrated in a number of previous studies (Macmillan and Copher 2005; Osgood et al 2005; Ross et al 2009; Sandefur, Eggerling-Boeck and Park 2005). Each of the four papers in this Special Section identifies 3 to 5 distinct role combinations, describing the coordination of work and familyrelated roles and independent living. The profiles of the different groups can be summarized as those characterized as work orientation without children, traditional families, highly educated, slow starters, and fragile families.

In interpreting the findings, one has to be aware that the status configurations of cohort members in their mid-20s represent only a snapshot in time, and do not capture the dynamics of transition processes. For example, "Slow Starters" living with their parents, might have returned to the parental home following a relationship breakdown or a career break. Of course, extending the one-time assessment with longitudinal data following individuals as they experience the various transitions, can provide a stronger case for mapping transitions (say with latent transition analysis) and examining their effects (Macmillan and Copher 2005; Macmillan and Eliason 2003; Muthén and Muthén 2000); such approaches bring in new problems (e.g. attrition). In any event, future research building on ours presented here, can bring a more dynamic approach to comparative analyses. Another limitation of latent class analysis lies in the temptation to attach too much meaning to a latent class or the label assigned to it (Sandefur et al 2005). One has to remain cautious in interpreting the group allocations, especially in regard to reifying labels assigned to the classes for easier interpretations. However, being able to identify similar groupings of role combinations across cohorts and across countries, indicates robustness of the approach and generalizability of findings.

\section{Comparative research}

Comparative research methods are used in cross-cultural studies to identify, analyse and explain similarities and differences across societies. A major issue to be addressed concerns the agreement over conceptual and functional equivalence of the research parameters (Hantrais and Mangen 1996; Ragin 1991). Attempts to find solutions to these problems involve negotiation and compromise and a sound knowledge of different national contexts. The studies represented in this Special Section are not based on a harmonised data set. The data collection in the different countries was not designed for comparative analysis, and is strongly influenced by national conventions. Furthermore, the sampling frames for data collection were not similar in the different countries, involving large scale prospective cohort and panel data, as well as, in the Finnish case, a small scale community sample. The purpose for which the data were gathered, the criteria used and the method of collection varied considerably from one country to another, and the criteria adopted for coding data has changed over time. For example, regarding the coding of educational attainment, differences in the 
structure of the three countries' education system make a direct comparison difficult. Furthermore, because post-secondary education sometimes extends throughout the $20 \mathrm{~s}$ in the US, current college attendance at age 26 is coded as a separate variable in the US study, in addition to information on employment status and highest qualifications achieved. In addition, in the 1966 Northern Finland Study, no information on part-time employment has been collected, and no differentiation between single, cohabiting, divorced, or widowed family status has been coded. Identifying comparative indicators of social roles was thus not always as straightforward as we hoped for, and in some cases the available information is limited. As a solution, we reduced the classifications of the transition markers to a common base, jointly agreeing on the parameters and units of comparison, and using the best possible data for comparison within and across countries. Regarding predictors, all studies have indicators of parental social status and family structure. Regarding outcomes, the different studies use different indicators of health and well-being, ranging from indicators of depression to marijuana use. All four studies have indicators of life satisfaction though, which is the comparative indicator of well-being.

\section{Conclusions and implications}

This Special Section represents an important step in placing the transitions from adolescence to adulthood within the appropriate context. Together, the four studies show the relevance of structural, developmental, national, and historical factors in shaping transitions; the variation and diversity in the transition to adulthood; developmental continuities from adolescence; the importance of objective markers and their combination as predictors of well-being; and the need for a broader definition of what comprises a "successful" transition to adulthood. Although the later-born cohorts in each country are better educated and more likely to be single and without children at age 26 compared to the earlier-born cohorts, the distinct patterns of role combinations largely remains unchanged within each country, not supporting the assumption of an increasing destandardization of the transition patterns. What we do see, however, is a polarization of fast versus slow transition prevalences, with those from less privileged backgrounds making the transition to parenthood earlier than others, consistent with the increased marginalization of those without sufficient resources to take advantage of educational opportunities during this transition (Heinz 2009; Macmillan 2005; Schoon and Silbereisen 2009). There are differences between and within the three countries regarding the patterns of role combinations as well as access to and selection of different pathways, depending on institutional filters (e.g. welfare systems), structural factors (e.g. social-economic background, family stability and gender), and individual characteristics and life plans, highlighting the importance of a contextualized and developmental understanding of transition experiences. Across the three countries and two birth cohorts, there is more than just one pattern of role configurations corresponding to high life satisfaction and wellbeing. In particular, the active engagement in and commitment to meaningful social roles predict higher levels of life satisfaction and well-being, highlighting the importance of reaching objective developmental tasks during the transition to adulthood (Schulenberg et al 2004). The timetable when to achieve certain tasks, however, appears to be variable and depends on the resources available to the individual.

For good reason, developmental scientists rarely talk anymore about universality of stages and sequences of development. The understanding and demonstration that the occurrence and meaning of developmental milestones depend on the multi-level context in which the individual is embedded, yield little justification for conceptualizing universalities in development (e.g. Conger, Conger and Martin 2010). Yet, when we find, as we do across the four papers in this Special Section, that there are many points of commonality in the experience of the transitions from adolescence to adulthood across three countries, with distinct customs and expectations about this transition, and across two birth cohorts who grew up in quite different economies, we gain an appreciation for some coherence and consistency of individual experiences, especially within social demographic groups. This coherence of 
experiences across time and space highlights the clear advantage of cross-country and cross-cohort comparisons, for they allow more convincing conclusions about commonalities and uniqueness of experiences across the transition to adulthood.

What we show here is one way to conduct cross-study and cross-national comparisons in terms of parallel analyses. Replication of research findings across independent longitudinal studies is essential for advancing developmental science. Other more intensive approaches (integrative or pooled data analysis) become available when there are common measures across studies (Curran and Hussong 2009). However, the complexity of longitudinal designs and cross-study differences in sample composition and measurements often impede or lessen the utility of such approaches. Nonetheless, a collaborative, coordinated analytic approach can provide needed leverage and a broad foundation for cumulating scientific knowledge, by facilitating efficient analysis of multiple studies in ways that maximize comparability of results, and permit evaluation of study differences (Hofer and Piccinin 2009). Future steps, building on what we have here, include extending this framework across other countries, time periods, and constructs, to get a fuller multi-level understanding of this pivotal time of life.

\section{Acknowledgments}

Work on this manuscript and special journal section was supported in part by grants from the National Institute on Drug Abuse Grant (R01 DA01411, R01 DA016575), the National Institute of Alcohol Abuse and Alcoholism (R01 AA019606, R21 AA020045), the UK Economic and Social Research Council (ESRC: RES-594-280001), and the National Science Foundation (BCS 0818478) to the Integrative Research Activities for Developmental Science (IRADS) Collaborative on Contexts Affecting Pathways from Childhood to Adulthood. The findings and conclusions in this report are those of the authors and do not necessarily represent the views of the NIH, ESRC, or NSF.

\section{References}

Arnett JJ. (2000) Emerging Adulthood. A theory of development from the late teens to the late twenties. American Psychologist, 55, 469-480.

Beck U. (1992) Risk Society. Towards a new modernity. Sage, London.

Blossfeld HP. (2005) Globalization, uncertainty and youth in society. Routledge, London.

Buchmann MC and Kriesi I. (2011) Transition to adulthood in Europe. Annual Review of Sociology, 37, 481503.

Burt KB and Masten AS. (2010) Development in the transition to adulthood: Vulnerabilities and opportunities. In JE Grant and MN Potenza. eds. Young adult mental health. Pp 5-18. Oxford University Press, New York.

Bynner J. (2005) Rethinking the youth phase of the life course: The case for emerging adulthood. Youth and Society, 8, 367-384.

Coleman JC. (1989) The focal theory of adolescence: A psychological perspective. In K Hurrelmann and U Engel. eds. The social world of adolescents: International perspectives. Pp 43-56. Walter de Gruyter, Oxford.

Conger RD, Conger KJ and Martin MJ. (2010) Socioeconomic status, family processes, and individual development. Journal of Marriage and Family, 72, 685-704. doi: 10.1111/j.1741-3737.2010.00725.x

Cook TD and Furstenberg FF. (2002) Explaining aspects of the transition to adulthood in Italy, Sweden, Germany, and the United States: A cross-disciplinary, case synthesis approach. Annals of the American Academy of Political and Social Science, 580, 257-287. doi: $10.1177 / 0002716202580001011$

Curran PJ and Hussong AM. (2009) Integrative data analysis: The simultaneous analysis of multiple data analysis. Psychological Methods, 14, 81-100. 
Dannefer D. (1987) Aging as intracohort differentiation: Accentuation, the Matthew effect, and the life course. Sociological Forum, 2, 211-236. doi: 10.1007/bf01124164

Elder GH. ed. (1985) Life course dynamics: Trajectories and transitions. Cornell University Press, Ithaca, NY.

Giddens A. (1991) Modernity and self-identity: Self and society in the late modern age. Polity Press, Cambridge.

Goodman LA. (1974) Explanatory latent structure analysis using both identifiable and unidentifiable models. Biometrika, 61, 215-231. doi: 10.1093/biomet/61.2.215

Hantrais L and Mangen S. (1996) Cross-national research methods in the social sciences. London, Pinter.

Heckhausen J. (2010) Globalization, social inequality, and individual agency in human development: Social change for better or worse? In RK Silbereisen and X Chen. eds. Social change and human development: Concepts and results. Pp 148-163. Sage, Thousand Oaks, CA.

Heinz WR. (2009) Structure and agency in transition research. Journal of Education and Work. Special issue: Continuity and change in 40 years of school to work transitions, 22, 391-404.

Hofer SM and Piccinin AM. (2009) Integrative data analysis through coordination of measurement and analysis protocol across independent longitudinal studies. Psychological Methods, 14, 150-164. doi: 10.1037/a0015566

Jensen LA. ed. (2011) Bridging cultural and developmental approaches to psychology: New synthesis in theory, research, and policy. Oxford University Press, New York.

Johnson MK, Crosnoe R and Elder GH. (2011) Insights on adolescence from a life course perspective. Journal of Research on Adolescence, 21, 273-280.

Lazarsfeld PF and Henry NW. (1968) Latent structure analysis. Houghton Mifflin, Boston.

Macmillan R. ed. (2005) The structure of the life course: Standardized? Individualized? Differentiated? Elsevier, Amsterdam.

Macmillan R and Copher R. (2005) Families in the life course: Interdependency of roles, role configurations, and pathways. Journal of Marriage and the Family, 67, 858-879.

Macmillan R and Eliason S. (2003) Characterizing the life course as role configurations and pathways: A latent structure approach. In JT Mortimer and MJ Shanahan eds. Handbook of the life course Pp 529-554. New York, Plenum.

Maggs JL, Jager J, Patrick ME and Schulenberg J. (2012) Social role patterning in early adulthood in the USA: adolescent predictors and concurrent wellbeing across four distinct configurations. Longitudinal and Life Course Studies, 3, 190-210.

Modell J, Furstenberg $\mathrm{G}$ and Hershberg T. (1976) Social change and transitions to adulthood in historical perspective. Journal of Family History, 1, 7-32.

Muthén BO and Muthén LK. (2000) Integrating person-centered and variable-centered analyses: Growth mixture modeling with latent trajectory classes. Alcohol: Clinical and Experimental Research, 24, 882-891.

Osgood DW, Ruth G, Eccles JS, Jacobs JE and Barber BL. (2005) Six paths to adulthood. In RA Settersten Jr, FF Furstenberg and RG Rumbaut. eds. On the frontier of adulthood. Theory, research and public policy Pp 320-355. The University of Chicago Press, Chicago.

Ragin CC. (1991) The problem of balancing discourse on cases and variables in comparative social science. CA, Sage Publications, Los Angeles.

Räikkönen E, Kokko K and Pulkkinen L. (2012) Patterns of adult transitions, their antecedents and correlates among Finns born in 1959. Longitudinal and Life Course Studies, 3, 211-227.

Rindfuss RR. (1991) The young adult years: Diversity, structural change, and fertility. Demography, 28, 493512.

Ross A, Schoon I, Martin P and Sacker A. (2009) Family and nonfamily role configurations in two British cohorts. Journal of Marriage and the Family, 71, 1-14. doi: 10.1111/j.1741-3737.2008.00576.x

Sacker A and Cable N. (2010) Transitions to adulthood and psychological distress in young adults born 12 years apart: Constraints on and resources for development. Psychological Medicine, 40, 301-313. doi: doi:10.1017/S0033291709006072

Salmela-Aro K, Ek E and Chen M. (2012) Role configurations in young adulthood, antecedents, and later wellbeing among Finns born in 1966. Longitudinal and Life Course Studies, 3, 228-242.

Sandefur GD, Eggerling-Boeck J and Park H. (2005) Off to a good start? Postsecondary education and early adult life. In RA Settersten Jr, FF Furstenberg and RG Rumbaut. eds. On the frontier of adulthood. Theory, research and public policy. Pp 356-395. The University of Chicago Press, Chicago.

Schoon I, Kneale D, Jager J and Chen M. (2012) Becoming adults in Britain: lifestyles and wellbeing in times of social change. Longitudinal and Life Course Studies, 3, 173-189. 
Schoon I and Silbereisen KR. eds. (2009) Transitions from school to work: Globalisation, individualisation, and patterns of diversity. Cambridge University Press, New York.

Schulenberg JE, Bryant AL and O'Malley PM. (2004) Taking hold of some kind of life: How developmental tasks relate to trajectories of well-being during the transition to adulthood. Development and Psychopathology, 16, 1119-1140.

Schulenberg JE and Maggs JL. (2002) A developmental perspective on alcohol use and heavy drinking during adolescence and the transition to young adulthood. Journal of Studies on Alcohol and Drugs 14, 5470.

Schulenberg JE, Maggs JM and O'Malley PM. (2003) How and why the understanding of developmental continuity and discontinuity is important: The sample case of long-term consequences of adolescent substance use. In JT Mortimer and MJ Shanahan. eds. Handbook of the life course. Pp 413-436. Plenum Publishers, New York.

Schulenberg JE and Zarrett NR. (2006) Mental health during emerging adulthood: Continuity and discontinuity in courses, causes, and functions. In JJ Arnett and JL Tanner. eds. Emerging adults in America: Coming of age in the 21st century. Pp 135-172. American Psychological Association, Washington DC.

Settersten RA Jnr. (2007) The new landscape of adult life: Road maps, signposts, and speed lines. Research in Human Development, 4, 239-252.

Shanahan MJ. (2000) Pathways to adulthood in changing societies: Variability and mechanisms in life course perspective. Annual Review of Sociology, 26, 667-692.

Shanahan MJ and Elder GH. (2006) History, human agency and the life course. University of Nebraska Press, Lincoln, NE.

Spear LP. (2010) The behavioral neuroscience of adolescence. Norton, New York. 